Article

\title{
In Vitro Antioxidant and Anti-Propionibacterium acnes Activities of Cold Water, Hot Water, and Methanol Extracts, and Their Respective Ethyl Acetate Fractions, from Sanguisorba officinalis L. Roots
}

\author{
Seongdae Kim ${ }^{1}$, Sung $\mathrm{Oh}^{1}$, Han Byul Noh ${ }^{1}$, Seongmi Ji ${ }^{1}$, Song Hee Lee ${ }^{1}$, Jung Mo Koo ${ }^{1}$, \\ Chang Won Choi ${ }^{1, *}$ and Hyun Pyo Jhun ${ }^{2}$ \\ 1 Department of Biology \& Medicinal Science, Pai Chai University, Daejeon 35345, Korea; \\ khboy111@pcu.ac.kr (S.K.); 5star@pcu.ac.kr (S.O.); creator1018@pcu.ac.kr (H.B.N.); \\ hijsm91@gmail.com (S.J.); thdgm16245@naver.com (S.H.L.); jungmo9@gmail.com (J.M.K.) \\ 2 Daeduck Lab. Co. Ltd., Daejeon 34024, Korea; hpjhon@daeducklab.com \\ * Correspondence: choicw@pcu.ac.kr; Tel.: +82-42-520-5617
}

Academic Editors: Natália Martins and Gertjan van Dijk

Received: 5 November 2018; Accepted: 14 November 2018; Published: 16 November 2018

check for updates

\begin{abstract}
Identification of medicinal plants and naturally derived compounds as new natural antioxidant and antibacterial sources for topical acne treatment has long been important. To determine anti-Propionibacterium acnes activity and in vitro antioxidant activities, Sanguisorba officinalis L. root (SOR) was extracted with cold water (CWE), hot water (HWE), and methanol (ME), and each extract was fractionated successively with hexane, ethyl acetate (EA), and butanol to determine whether the activities could be attributed to the total phenolic, flavonoid, terpenoid, and condensed tannin contents. Pearson's correlation coefficients were analyzed between the respective variables. The SOR CWE, HWE, ME, and their respective EA fractions showed anti-P. acnes activity based on the paper disc diffusion method on agar plates, minimum inhibitory concentration (MIC), and minimal bactericidal concentration (MBC). The MIC against P. acnes had a moderate $(+)$ correlation with the total phenolic content, but not with the other measures. The 2,2-diphenyl-1-picrylhydrazyl (DPPH) scavenging capacity (SC) had a strong (-) correlation with the total phenolic content and a moderate (-) correlation with the total flavonoid content. The total antioxidant capacity had a strong $(+)$ correlation with the condensed tannin content. Linoleic acid peroxidation inhibition had a strong (-) correlation with the total phenolic content. To elucidate the major active phytochemicals in the CWE-EA, HWE-EA, and ME-EA fractions, high performance liquid chromatography-ultraviolet (HPLC-UV) and ultra high performance liquid chromatography coupled with hybrid triple quadrupole time-of-flight mass spectrometry (UHPLC-QTOF-MS) were performed. The HPLC-UV analysis showed the presence of nine compounds in common (arjunic acid and/or euscaphic acid, gallic acid, kaempferol, caffeic acid, ferulic acid, tannic acid, and coumarin, quercetin). The UHPLC-QTOF-MS analysis showed the presence of nine compounds in common (gallic acid; caffeic acid; umbelliferone; arjunic acid, euscaphic acid, and/or tormentic acid; pomolic acid; rosamultic acid; and benzoic acid). When standards of the identified phytochemicals were tested against the same bacterium, quercetin, coumarin, and euscaphic acid showed antibacterial activity against $P$. acnes.
\end{abstract}

Keywords: Sanguisorba officinalis L. root; cold water extract; hot water extract; methanol extract; ethyl acetate fraction; anti-Propionibacterium acnes activity; in vitro antioxidant activities 


\section{Introduction}

Skin disorders, such as acne vulgaris and atopic dermatitis, are associated with inflammation and the release of free radicals, which lead to oxidative and cellular damage, and bacterial infections. Acne vulgaris affects the face, back, shoulders, and chest, which contain the largest oil glands, and contributes to an increase in sebum excretion, comedogenesis, Propionibacterium acnes proliferation, and inflammation [1]. P. acnes acts as an immunostimulator through the production of proinflammatory cytokines, which are involved in development of the inflammatory process [2]. Inhibition of $P$. acnes decreases comedone rupture into the surrounding skin and prevents acne progression.

Topical application of therapeutic agents has been found to be more feasible than hormonal treatment and laser therapy. Available synthetic treatments using topical benzoyl peroxide and retinoid are effective for mild acne [3]. However, benzoyl peroxide can induce side effects, such as concentration-dependent irritation and uncommon contact allergy [4]. Retinoid is also limited by side effects (dryness, peeling, erythema, and irritation) and risk of photosensitivity [3]. For mild or moderate acne, topical antibiotics, such as clindamycin and erythromycin, are used as medications, however use of topical antibiotics in combination with benzoyl peroxide is recommended due to increasing antibiotic resistance [4]. Use of oral antibiotics for moderate or severe acne can have several side effects, including photosensitivity, gastrointestinal distress, and Candida infections [5]. Moreover, their chronic use can lead to the development of drug-resistant bacteria [6,7]. In this respect, the ingredients in topical acne treatments, particularly herbs and naturally derived compounds, have received considerable interest, because they show fewer adverse effects than synthetic agents [8].

Sanguisorba officinalis L. is a member of the Rosaceae family and is a widely distributed perennial weed worldwide [9]. Edible dried roots of S. officinalis L. (known as JiYu in Korea and Japan or DiYu in China) have been used as a herbal medicine for centuries. Traditionally, S. officinalis L. root (SOR) has been used in Far East countries for multiple purposes, including hemostasis in hypermenorrhea and internal or external bleeding, and treatment for scalds and burns, frostbite, diarrhea, chronic intestinal infections, and duodenal ulcers [10,11]. Experimentally, Sanguisorba species have shown anti-Alzheimer's [9], anticancer [12-16], anti-inflammatory [9,17,18], antioxidant [19-21], antiviral [22,23], and anti-wrinkle [24] activities. These pharmacological studies have led to the isolation of several compounds, including triterpenoids, phenolic acids, flavonoids, phenylpropanoids, and polysaccharides $[9,11,12,24-29]$.

In particular, SOR is known to be effective against skin diseases, including urticaria, eczema, and allergic dermatitis [30], and against numerous bacteria [31-33]. However, antibacterial activity against $P$. acnes has not been reported. The aim of this study was to evaluate antibacterial activity against $P$. acnes, and the in vitro antioxidant activities of SOR. To determine whether these activities can be attributed to the total phenolic, flavonoid, terpenoid, and condensed tannin contents, SOR was extracted using cold water (CWE), hot water (HWE), and methanol (ME), and the respective extracts were further fractionated successively with hexane, ethyl acetate (EA), and butanol using separating funnels. To determine the major active phytochemicals in the respective EA fractions, high performance liquid chromatography-ultraviolet (HPLC-UV) and ultra high performance liquid chromatography coupled with triple quadrupole time-of-flight mass spectrometry (UHPLC-QTOF-MS) was performed.

\section{Results}

2.1. Total Phenolic, Flavonoid, Terpenoid, and Condensed Tannin Contents in the CWE, HWE, ME, and their Respective EA Fractions

As shown in Table 1, selected phytochemicals varied among the extracts and their derived EA fractions. Among three different extracts, the HWE showed the highest total phenolic, flavonoid, and condensed tannin contents (60.0 mg gallic acid equivalent (GAE)/g, $30.2 \mathrm{mg}$ quercetin equivalent $(\mathrm{QE}) / \mathrm{g}$, and $1.80 \mathrm{mg}$ catechin equivalent (CE)/g dry powder, respectively), while the CWE showed the highest total terpenoid content of $29.10 \mathrm{mg} / \mathrm{g}$ powder. Among three different EA fractions, 
CWE-EA showed the highest total phenolic, flavonoid, terpenoid, and condensed tannin contents (58.1 mg GAE/g, $20.9 \mathrm{mg} \mathrm{QE/g,} 29.69 \mathrm{mg} / \mathrm{g}$, and $2.15 \mathrm{mg} \mathrm{CE} / \mathrm{g}$ dry powder, respectively).

Table 1. Total phenolic, flavonoid, terpenoid, and condensed tannin contents in various extracts and their respective fractions of $S$. officinalis L. roots.

\begin{tabular}{ccccc}
\hline Extract/Fraction & $\begin{array}{c}\text { Total Phenolic } \\
\text { Content } \\
\text { (mg GAE/g } \pm \text { SD) }\end{array}$ & $\begin{array}{c}\text { Total Flavonoid } \\
\text { Content } \\
\text { (mg QE/g } \pm \text { SD) }\end{array}$ & $\begin{array}{c}\text { Total Terpenoid } \\
\text { Content } \\
\text { (mg/g } \pm \text { SD) }\end{array}$ & $\begin{array}{c}\text { Condensed } \\
\text { Tannin Content } \\
\text { (mg CE/g } \pm \text { SD) }\end{array}$ \\
\hline CWE & $59.0 \pm 0.57^{\mathrm{d}}$ & $20.6 \pm 0.39^{\mathrm{ab}}$ & $29.10 \pm 0.000^{\mathrm{c}}$ & $1.69 \pm 0.058^{\mathrm{b}}$ \\
HWE & $60.0 \pm 1.15^{\mathrm{d}}$ & $30.2 \pm 2.46^{\mathrm{c}}$ & $27.40 \pm 0.001^{\mathrm{b}}$ & $1.80 \pm 0.004^{\mathrm{c}}$ \\
ME & $46.1 \pm 3.3^{\mathrm{c}}$ & $17.9 \pm 0.81^{\mathrm{a}}$ & $22.38 \pm 0.001^{\mathrm{a}}$ & $1.14 \pm 0.001^{\mathrm{a}}$ \\
CWE-EA & $58.1 \pm 1.89^{\mathrm{d}}$ & $20.9 \pm 0.34^{\mathrm{ab}}$ & $29.69 \pm 0.001^{\mathrm{c}}$ & $2.15 \pm 0.002^{\mathrm{e}}$ \\
HWE-EA & $38.3 \pm 2.41^{\mathrm{b}}$ & $20.1 \pm 0.92^{\mathrm{ab}}$ & $26.29 \pm 0.001^{\mathrm{b}}$ & $2.06 \pm 0.001^{\mathrm{ab}}$ \\
ME-EA & $25.6 \pm 1.99^{\mathrm{a}}$ & $18.2 \pm 2.31^{\mathrm{ab}}$ & $29.68 \pm 0.001^{\mathrm{c}}$ & $1.73 \pm 0.007^{\mathrm{ab}}$ \\
\hline
\end{tabular}

CWE: cold water extract; HWE: hot water extract; ME: methanol extract; CWE-EA: ethyl acetate fraction of the CWE; HWE-EA: ethyl acetate fraction of the HWE; ME-EA: ethyl acetate fraction of the ME. GAE: gallic acid equivalent; QE: quercetin equivalent; CE: catechin equivalent. g: dry powder weight. The data shown represent the mean values of triplicate assays and standard deviations (SDs). Values in the same column followed by a different letter are significantly different using Duncan's multiple range test at the $5 \%$ level $(p<0.05)$.

\subsection{Antibacterial Activities of the CWE, HWE, ME, and their Respective EA Fractions}

The CWE and HWE were active only against P. acnes and were not active against other bacteria. However, the ME showed antibacterial activity against all tested bacteria in the paper disc diffusion assay (Table S1). Therefore, we focused on the antibacterial activity against P. acnes, which was evaluated by the paper disc diffusion assay, minimum inhibitory concentration (MIC), and minimum bactericidal concentration (MBC). In the paper disc diffusion assay (Figure 1), the inhibition zone increased in a concentration-dependent manner, reaching its maximum size at a $5 \mathrm{mg} /$ disc concentration for all extracts $(24.0-24.5 \mathrm{~mm})$ and their EA fractions $(28.0-28.5 \mathrm{~mm})$. The kanamycin control showed a $30.5 \mathrm{~mm}$ inhibition zone size against $P$. acnes (data not shown). The MIC values of the CWE, HWE, and ME were 1250, 625, and $312 \mu \mathrm{g} / \mathrm{mL}$, respectively, and their MBC values were 2500, 1250, and $312 \mu \mathrm{g} / \mathrm{mL}$, respectively. The MIC values of the CWE-EA, HWE-EA, and ME-EA were 312,156 , and $78 \mu \mathrm{g} / \mathrm{mL}$, respectively, and their MBC values were 312, 312, and $156 \mu \mathrm{g} / \mathrm{mL}$, respectively (Table 2).

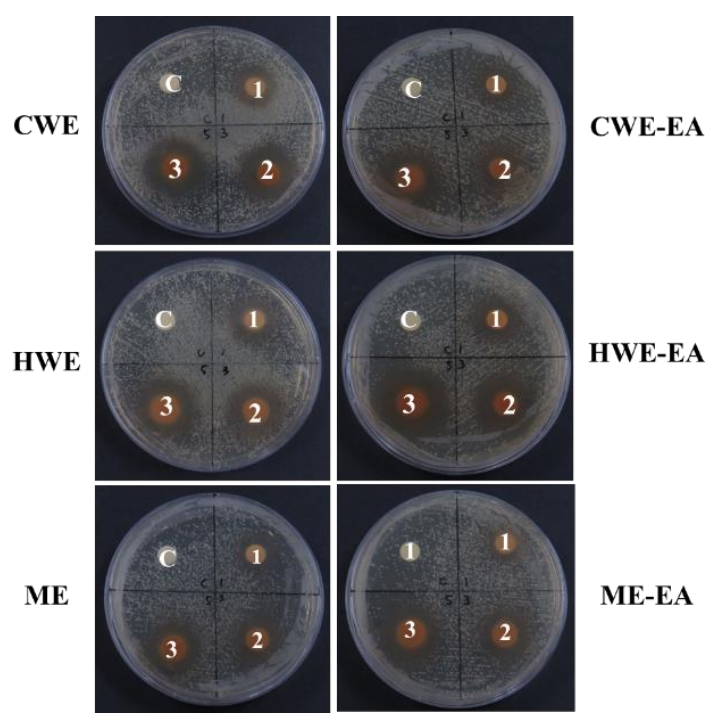

Figure 1. Determination of inhibition zones against $P$. acnes using the paper disc diffusion method on agar plates. The treated concentrations were $1 \mathrm{mg} / \mathrm{mL}(1), 3 \mathrm{mg} / \mathrm{mL}$ (2), and $5 \mathrm{mg} / \mathrm{mL}$ (3) of the S. officinalis L. root (SOR) CWE, HWE, ME, and their derived ethyl acetate fractions (CWE-EA, HWE-EA, and ME-EA). The negative control (C) in each sample is DMSO. 
Table 2. Minimum inhibitory concentration (MIC) and minimum bactericidal concentration (MBC) against $P$. acnes of various extracts from $S$. officinalis $L$. and their ethyl acetate fractions.

\begin{tabular}{ccc}
\hline Extract \& Fraction & MIC $(\mu \mathrm{g} / \mathbf{m L})$ & MBC $(\mu \mathrm{g} / \mathbf{m L})$ \\
\hline CWE & 1250 & 2500 \\
HWE & 625 & 1250 \\
ME & 312 & 312 \\
CWE-EA & 312 & 312 \\
HWE-EA & 156 & 312 \\
ME-EA & 78 & 156 \\
\hline
\end{tabular}

\subsection{In Vitro Antioxidant Activity of the CWE, $H W E, M E$, and their Respective EA Fractions}

In this study, the SOR CWE, HWE, ME, and their respective EA fractions exhibited a free radical scavenging capacity (SC) in a dose-dependent manner when the 2,2-diphenyl-1-picrylhydrazyl (DPPH) radical was used as a substrate (Figure 2). The HWE exhibited the best $\mathrm{SC}_{50}$ value of $7.58 \mu \mathrm{g} / \mathrm{mL}$, followed by the CWE $(12.14 \mu \mathrm{g} / \mathrm{mL}), \mathrm{ME}(16.74 \mu \mathrm{g} / \mathrm{mL})$, CWE-EA $(19.14 \mu \mathrm{g} / \mathrm{mL})$, HWE-EA $(35.81 \mu \mathrm{g} / \mathrm{mL})$, and ME-EA $(52.46 \mu \mathrm{g} / \mathrm{mL})$.
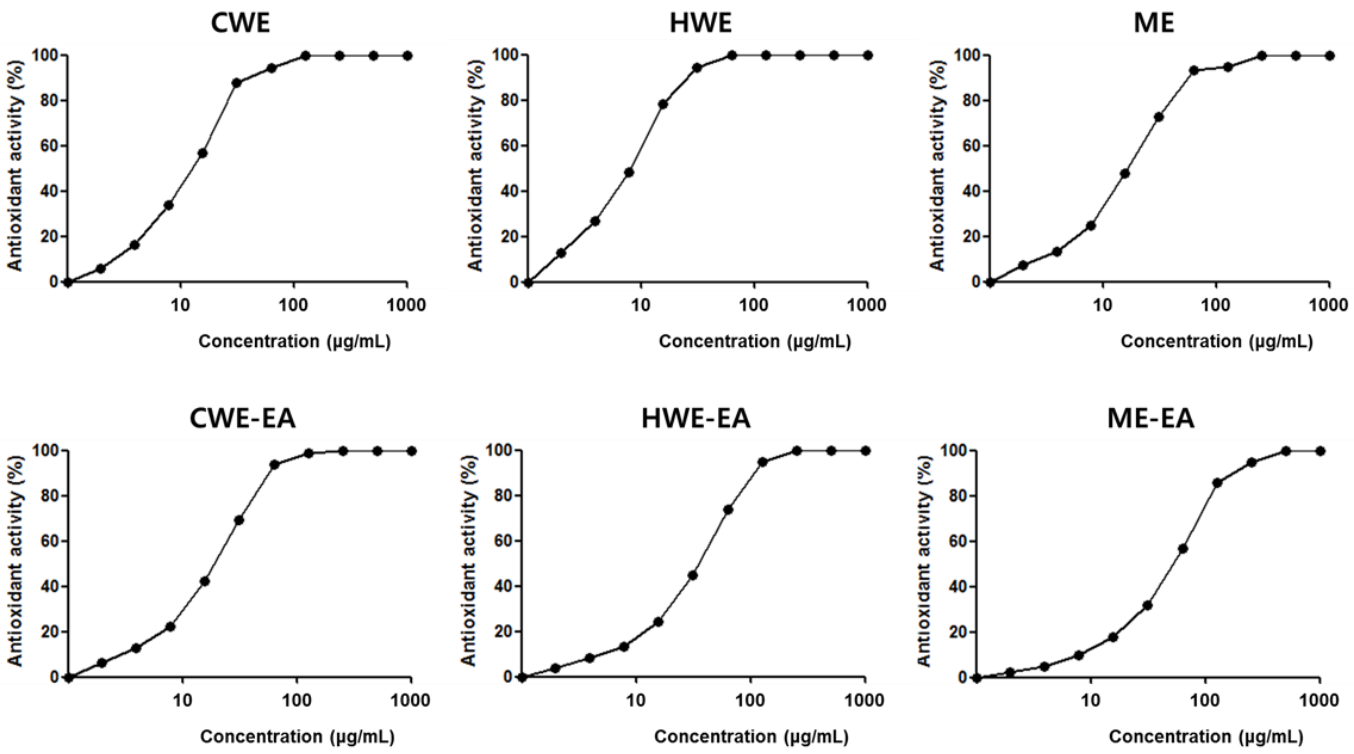

Figure 2. Scavenging capacity (SC) of the 2,2-diphenyl-1-picrylhydrazyl (DPPH) radical by the SOR CWE, HWE, ME, and their ethyl acetate fractions (CWE-EA, HWE-EA, and ME-EA). Each methanolic sample $(1 \mathrm{mg} / \mathrm{mL}$ in methanol) was further diluted using the two-fold method. The absorbance was measured against a blank at $517 \mathrm{~nm}$ and converted into the percentage SC using the following equation: $\%$ SC $=($ Absorbance of control - Absorbance of sample $) \times 100 /$ Absorbance of control. All tests were performed at least in triplicate, and the graphs were plotted using the average of three determinations.

The percentages of the total antioxidant capacity of the CWE, HWE, ME, and their respective EA fractions were in a range of 80.7 to $91.7 \%$ (Figure 3a). Although the HWE-EA value was lower than that of quercetin $(99.8 \%)$, no significant difference was found between the two values. The SC percentages for hydrogen peroxide for the $\mathrm{CWE}, \mathrm{HWE}, \mathrm{ME}$, and their respective EA fractions were in a range of 51.9 to $99.6 \%$ (Figure 3b). Among the extracts and their respective EA fractions, the SC value of the ME was close to that of quercetin (99.8\%). The percentage inhibition values of linoleic acid peroxidation for the CWE, HWE, ME, and their respective EA fractions were in a range of 58.3 to $79.8 \%$ (Figure 3c). The linoleic acid peroxidation inhibition value of the ME-EA was close to that of quercetin $(83.4 \%)$, and no significant difference was found between the two values. 
(a)

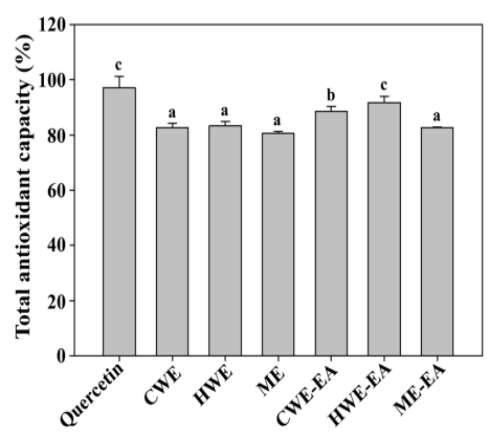

(b)

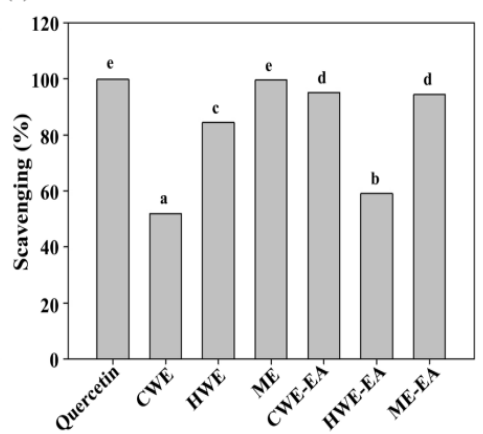

(c)

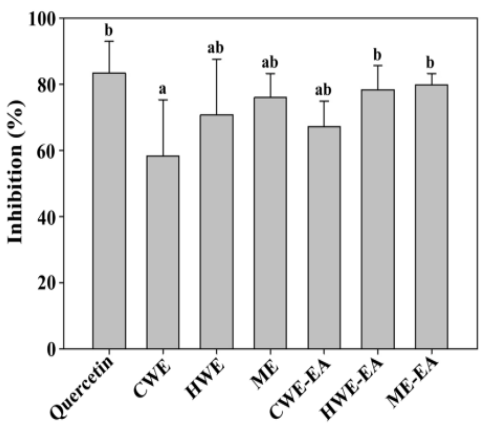

Figure 3. In vitro antioxidant activities of the SOR CWE, HWE, ME, and their respective ethyl acetate fractions (CWE-EA, HWE-EA, and ME-EA) at $1 \mathrm{mg} / \mathrm{mL}$ concentration. (a) The total antioxidant activity was determined spectrophotometrically at $765 \mathrm{~nm}$. (b) The $\mathrm{H}_{2} \mathrm{O}_{2}$ scavenging capacity (\%) was determined spectrophotometrically at $560 \mathrm{~nm}$. (c) The lipid peroxidation inhibition (\%) was determined by the thiobarbituric acid method at $535 \mathrm{~nm}$. All data is expressed as the mean $\pm \mathrm{SD}(n=3)$. Values with the same letter on each bar are not significantly different using Duncan's multiple range test at the $5 \%$ level $(p<0.05)$.

\subsection{HPLC-UV and UHPLC-QTOF-MS Analyses}

The retention times of the peaks detected from the HPLC-UV chromatograms of the CWE-EA, HWE-EA, and ME-EA were compared to those of the reference standards tentatively proposed: (1) euscaphic acid or arjunic acid (or both), (3) gallic acid, (4) kaempferol, (5) caffeic acid, (6) ferulic acid, (7) tannic acid, (8) coumarin, (9) quercetin, and (10) chlorogenic acid at retention times of 2.0, 4.7, 20.5, 21.0, 27.8, 29.3, 31.5, 32.7, and $34.0 \mathrm{~min}$, respectively (Figure 4a). Eight peaks were identified in CWE-EA and HWE-EA, and nine peaks were identified in the ME-EA. Regardless of the EA fractions, tannic acid (a commercial form of tannin) showed the highest peak, followed by euscaphic and arjunic acids (Figure $4 b-d)$.
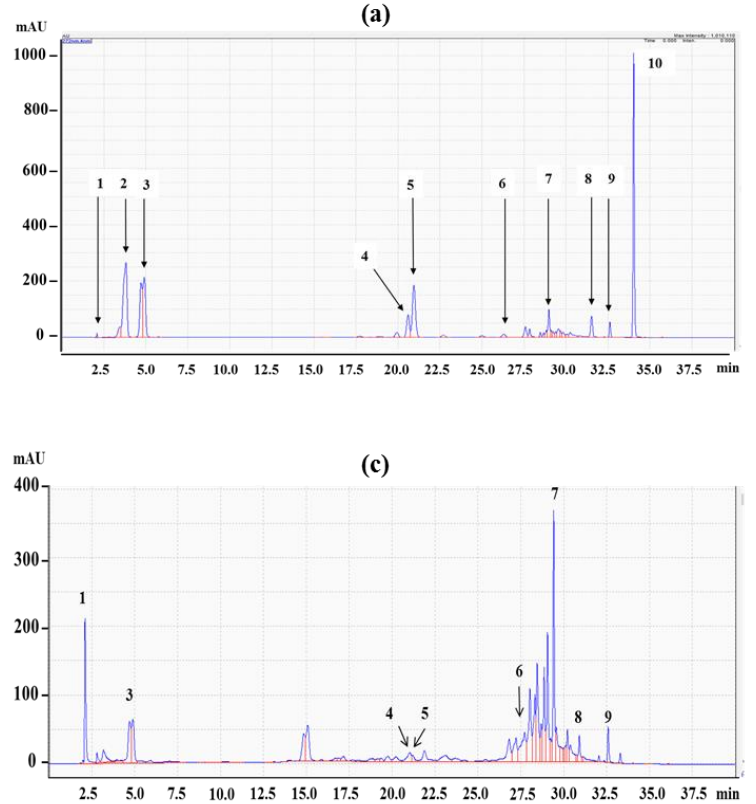

(b)

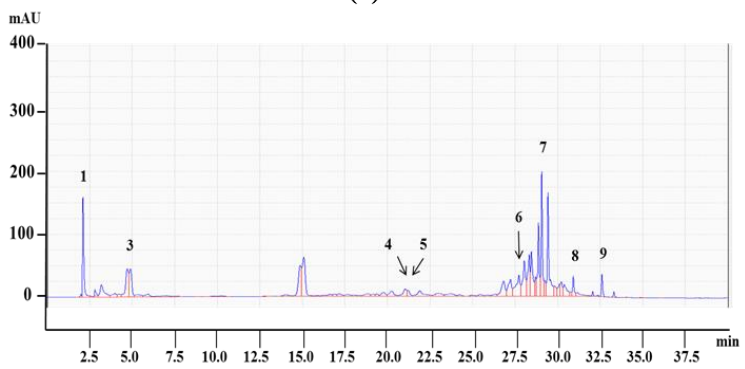

(d)

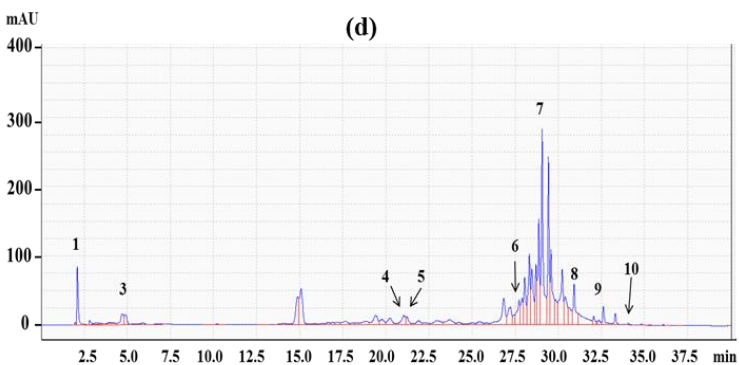

Figure 4. High performance liquid chromatography-ultraviolet (HPLC-UV) chromatograms (272 nm) of the mixed references solution (a), SOR CWE-EA (b), HWE-EA (c), and ME-EA (d). The numbers represent euscaphic acid and/or arjunic acid (1), comic acid (2), gallic acid (3), kaempferol (4), caffeic acid (5), ferulic acid (6), tannic acid (7), coumarin (8), quercetin (9), and chlorogenic acid (10). 
To validate the proposed nine phytochemicals, CWE-EA, HWE-EA, and ME-EA were further analyzed by UHPLC-QTOF-MS. The MS data and the tentative identification results are shown in Table 3, Figure 5, and Supplementary Figures S1 and S2. The UHPLC-QTOF-MS analysis provides score, formula, intensity, accurate mass, and retention time. In the CWE-EA, twelve compounds were tentatively identified with a mass error between $-0.9 \mathrm{ppm}$ and $-0.1 \mathrm{ppm}$. Their overall identification scores were higher than 92\%, except for rosamultic acid (54\%). In the HWE-EA, nineteen compounds were tentatively identified with a mass error between $-2.7 \mathrm{ppm}$ and $1.0 \mathrm{ppm}$, and they showed a broad range of identification scores between $94 \%$ (pomolic acid) and 51\% (catechin). In the ME-EA, nineteen compounds were tentatively identified with a mass error between $-1.0 \mathrm{ppm}$ and $1.0 \mathrm{ppm}$, and they showed a broad range of identification scores between 97\% (pomolic acid, benzoic acid) and $50 \%$ (catechin).

Table 3. MS data and the identification of compounds from CWE-EA, HWE-EA and ME-EA by UHPLC-QTOF-MS.

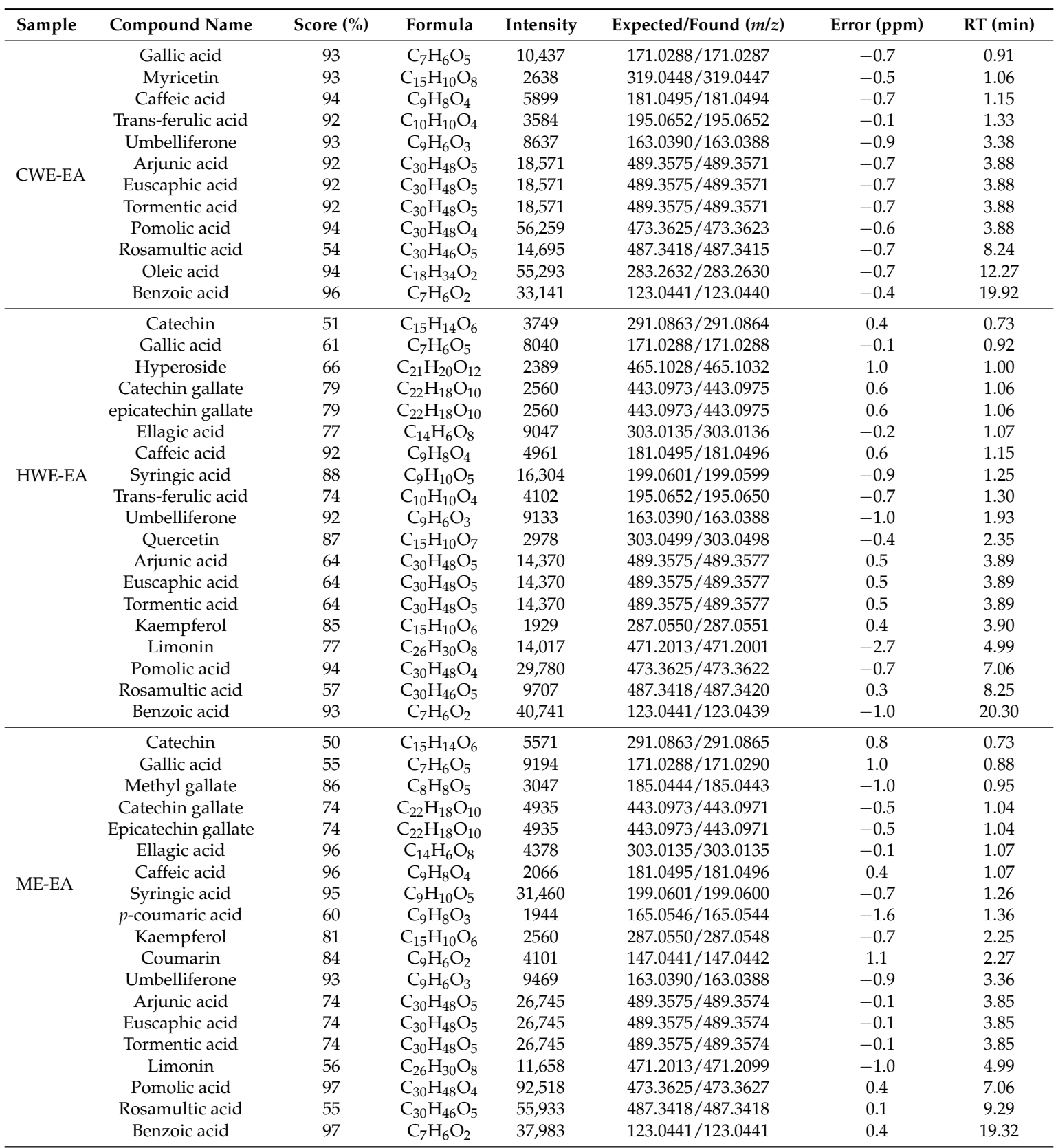


CATECHII

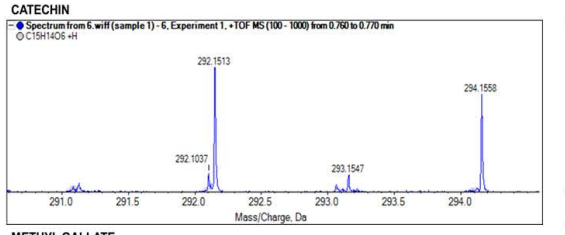

METHYL GALLATE

$$
\text { : }
$$

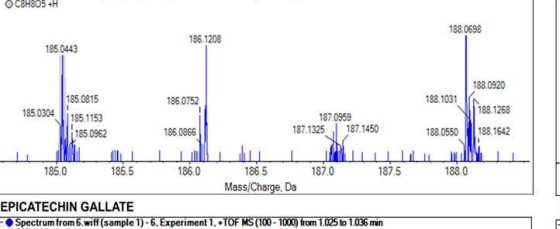

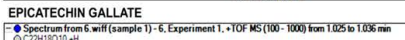

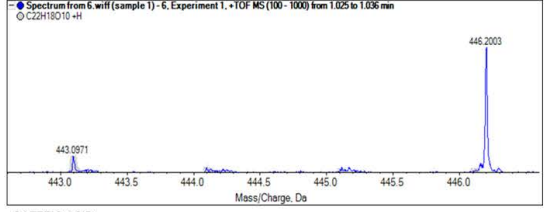

CAFFEIC AC

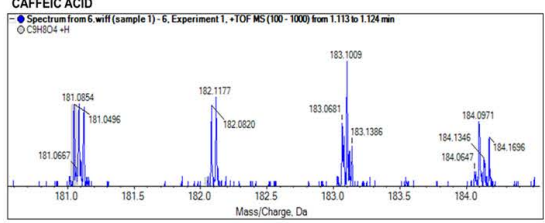

P.COUMARIC ACID

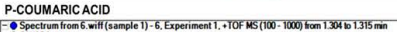

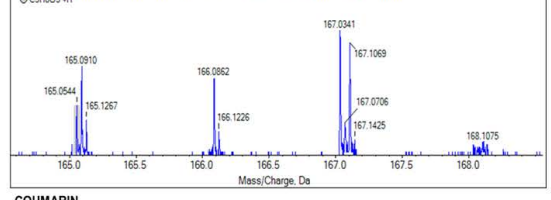

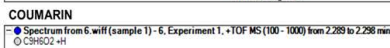

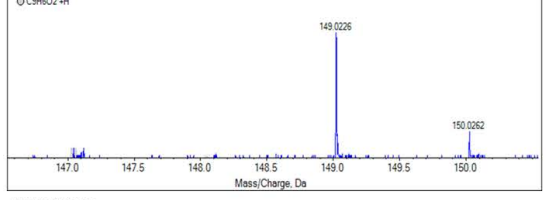

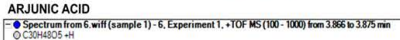

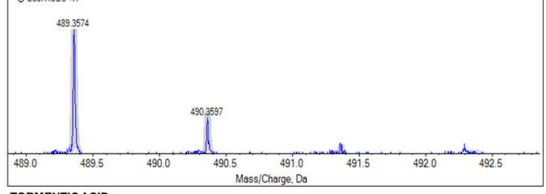

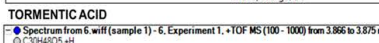

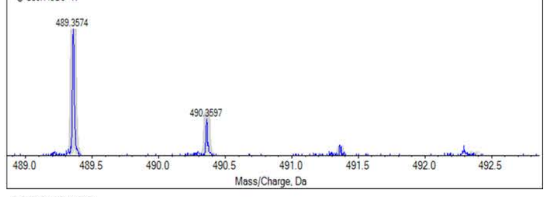

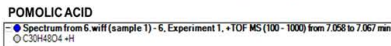

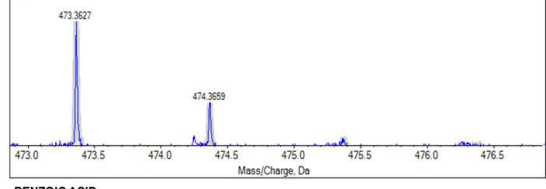

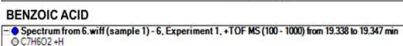

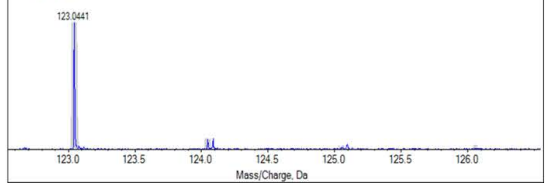

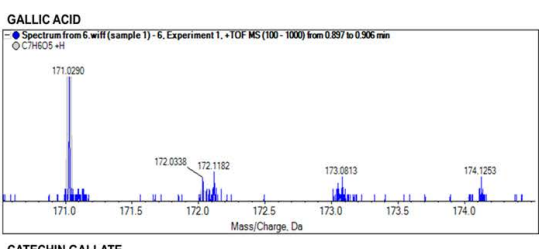

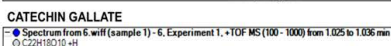

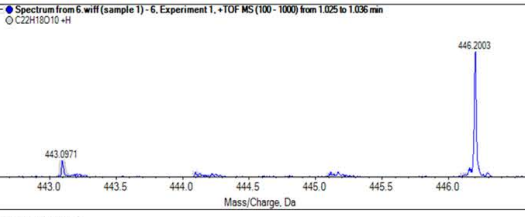

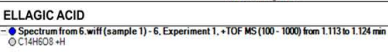
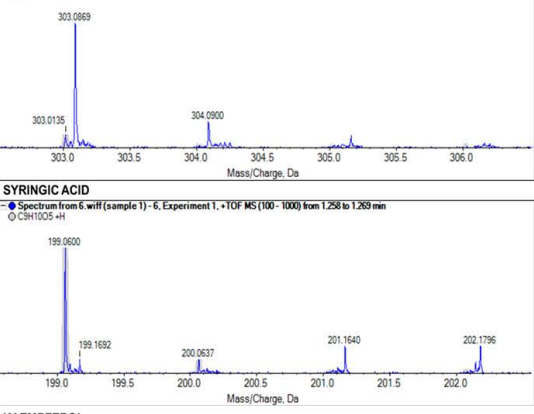

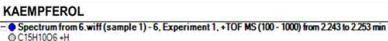

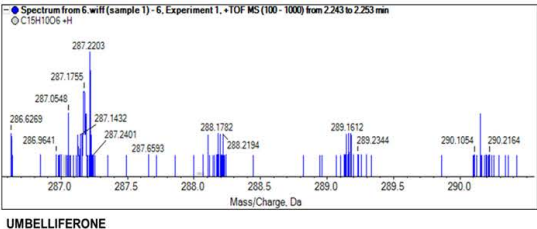

UMBELLFERONE

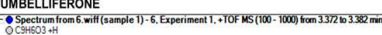

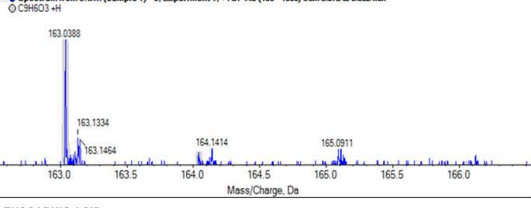

EUSCAPHIC ACID

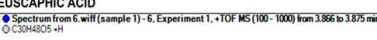
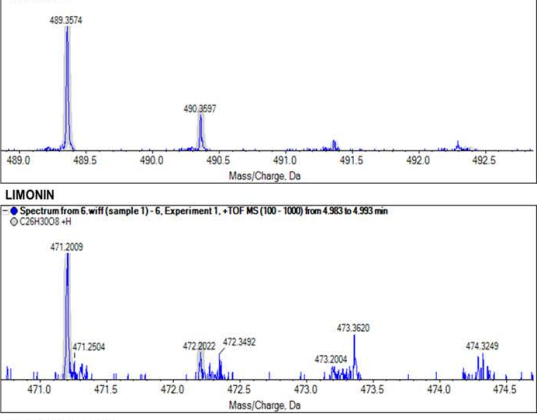

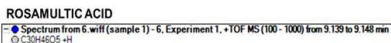

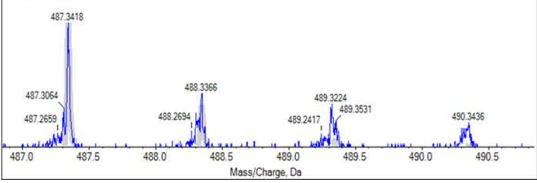

Figure 5. UHPLC-QTOF-MS spectra of major compounds in SOR ME-EA. 
Some compounds were found only in the CWE-EA (myricetin, oleic acid), HWE-EA (hyperoside, quercetin), or ME-EA (methyl gallate, $p$-coumaric acid, coumarin). However, all the EA fractions have nine compounds in common, such as gallic acid (molecular weight of 171.03), caffeic acid (molecular weight of 181.04), umbelliferone (molecular weight of 163.04), euscaphic acid (arjunic acid, tormentic acid) (molecular weight of 489.36), pomolic acid (molecular weight of 473.36), rosamultic acid (molecular weight of 487.34), and benzoic acid (molecular weight of 123.04). Three terpenoids (euscaphic acid, arjunic acid, tormentic acid) showed the same information of score, intensity, molecular mass, and retention time.

To confirm that the identified major compounds had anti-P. acnes activity, nine selected standards were tested using the paper disc diffusion method. In particular, coumarin showed the strongest inhibition of $P$. acnes growth, followed by quercetin and euscaphic acid. On the other hand, quercetin, kaempferol, ferulic acid, caffeic acid, gallic acid, tannic acid, and benzoic acid showed negative results (Figure 6).

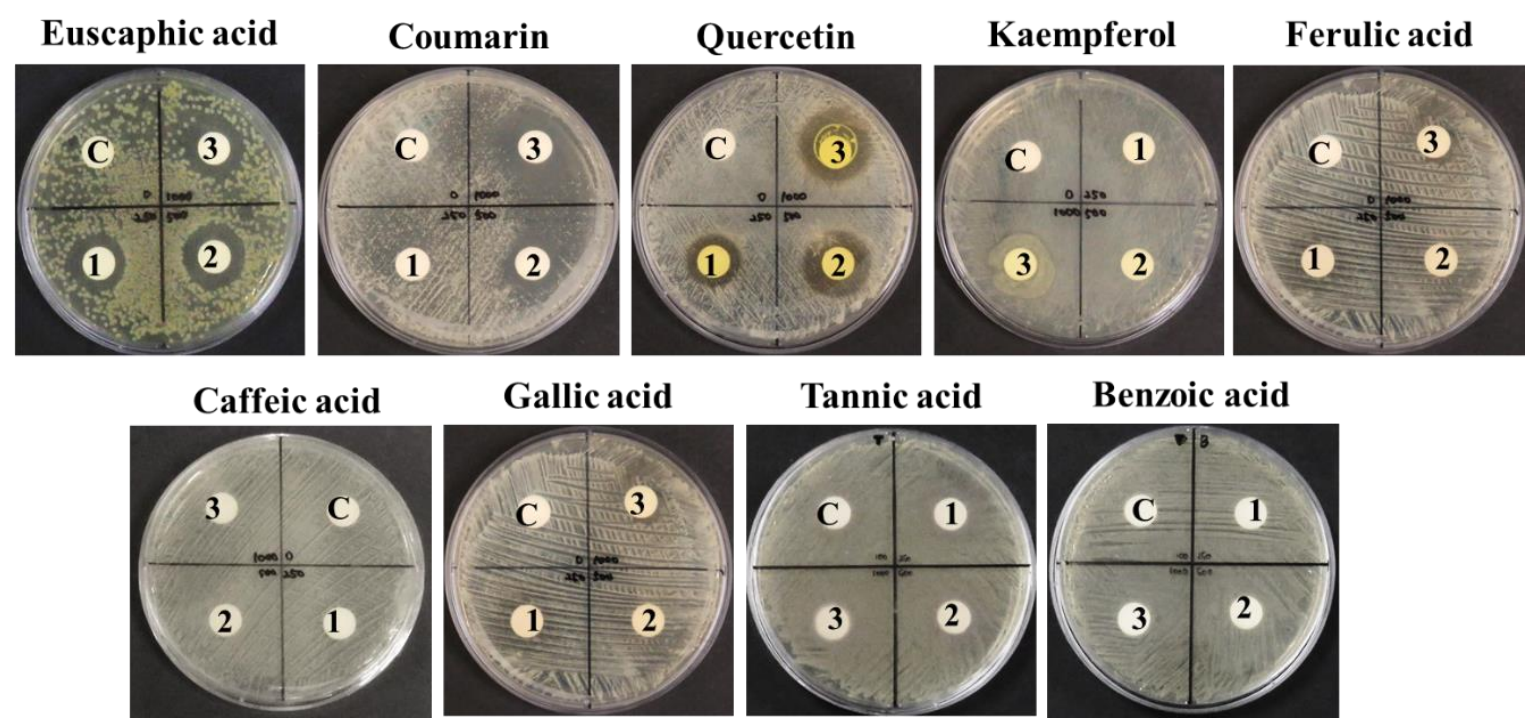

Figure 6. Effects of HPLC-identified compounds on the growth inhibition of P. acnes using the paper disc diffusion method on agar plates. The concentrations of the treated standard chemicals were DMSO-treated control (C), $250 \mu \mathrm{g} / \mathrm{mL}$ (1), $500 \mu \mathrm{g} / \mathrm{mL}$ (2), and $1000 \mu \mathrm{g} / \mathrm{mL}$ (3).

\section{Discussion}

In previous studies, either methanol or ethanol extracts of some plants showed higher total phenolic and flavonoid contents than the HWE [34,35]. In contrast, the SOR HWE showed higher total phenolic, flavonoid, and condensed tannin contents than the CWE and ME. Hot water extraction is therefore effective in extracting bioactive phytochemical constituents. The recovery of polyphenols from plant tissues is probably influenced by their solubility during extraction, the solvent type, the degree of phenol polymerization, the phenol-other constituent interaction, and insoluble complex formation [36].

Contrary to the previous study on water extracts from the aerial parts or leaves of S. officinalis L. [33], the SOR CWE and HWE showed antimicrobial activity against P. acnes. It is unclear whether the anti-P. acnes compounds are rich in the roots but not in the aerial parts of S. officinalis L. Among the extracts and their respective EA fractions, the SOR ME and ME-EA showed the lowest MIC and MBC values against $P$. acnes. Furthermore, the SOR ME and ME-EA showed antimicrobial activity against numerous Gram-negative and -positive bacteria, which corresponds to earlier works [31,37,38]. It suggested that the SOR ME displayed a broad spectrum of antibacterial activity, whereas both the CWE and HWE displayed a narrow spectrum of antibacterial activity. In a previous study, high total phenolic and flavonoid contents from ethanol extract of a plant showed strong correlation with high 
antibacterial activity [35]. In this study, Pearson's correlation analysis indicated that the MIC against $P$. acnes had a moderate $(+)$ correlation with the total phenolic content $(r=0.659, p=0.15)$, but weak correlations with the total flavonoid $(r=0.293)$, terpenoid $(r=0.235)$, and condensed tannin $(r=-0.130)$ contents. Although we could not predict clearly whether the total flavonoid, terpenoid, and condensed tannin contents were attributed to direct antibacterial activity against $P$. acnes, specific compounds in the extracts might be responsible for the effect.

In previous studies, the DPPH radical SC and antioxidant activities showed strong correlations with the total phenolic, flavonoid, or condensed tannin contents of many plant species [39-43]. In this study, Pearson's correlation analysis indicated that the DPPH SC had a strong (-) correlation with the total phenolic content $(\mathrm{r}=-0.946, p<0.01)$ and a moderate $(-)$ correlation with the total flavonoid content $(\mathrm{r}=-0.557)$ of SOR. However, the DPPH radical SC showed weak correlations with the condensed tannin $(r=0.181)$ and total terpenoid $(r=0.238)$ contents. The total antioxidant capacity had a strong $(+)$ correlation with the condensed tannin content $(\mathrm{r}=0.822, p<0.05)$, but showed weak correlations with the total phenolic $(r=-0.050)$, flavonoid $(r=-0.009)$, and terpenoid $(r=0.211)$ contents. The hydrogen peroxide SC showed weak correlations with the total phenolic $(r=-0.181)$, flavonoid $(\mathrm{r}=-0.072)$, terpenoid $(\mathrm{r}=-0.194)$, and condensed tannin $(\mathrm{r}=-0.299)$ contents. Linoleic acid peroxidation inhibition had a strong $(-)$ correlation with the total phenolic content $(\mathrm{r}=-0.826, p<0.05)$, but weak correlations with the total flavonoid $(r=-0.216)$, terpenoid $(r=-0.437)$, and condensed tannin $(r=-0.232)$ contents. Taken together, the Pearson's correlation coefficients suggest strong relationships between the DPPH SC and the total phenolic and flavonoid contents, between the total antioxidant activity and the condensed tannin content, and between linoleic acid peroxidation inhibition and the total phenolic content of SOR.

The combination of HPLC-UV and UHPLC-QTOF-MS proved an efficient method for the detection of compounds that are responsible for antimicrobial and antioxidant activities. The qualitative accuracy of the results was much increased by mutual confirmation, and false positive results were excluded. The HPLC-UV detected tannic acid $\left(\mathrm{C}_{76} \mathrm{H}_{52} \mathrm{O}_{46}, 1700 \mathrm{Da}\right)$ showing the highest peak, whereas the UHPLC-QTOF-MS failed to show this compound, because the analysis covers a mass range of 100-1000 m/z. Instead, the UHPLC-QTOF-MS showed the presence of gallic acid or ellagic acid (or both) in the all EA fractions, and these hydrolysable tannins are known to form gallototannins or ellagitannins. In addition, catechin, catechin gallate, and epicatechin gallate were identified in the HWE-EA and ME-EA, and their oligomers or polymers are known to form condensed tannins (procyanidins). Recently, several tannins were used as feed additives to control diseases in poultry farms [44] due to their antibacterial activity $[45,46]$.

Although ferulic acid, gallic acids [47], caffeic acid [48], and condensed tannins [49] are known to have antibacterial activity against some Gram-positive bacteria, they may not be responsible for the anti-P. acnes activity of SOR. The presence of such phenolics could be related to the considerable antioxidant activities (DPPH radical SC, total antioxidant capacity, hydrogen peroxide SC, and linoleic acid peroxidation inhibition) of SOR. Flavonoids are well-known antioxidants with antimicrobial properties [50], and these properties are related to their chemical structures, especially the numbers and positions of methoxyl and hydroxyl groups [29]. Chromatographic profiles also showed that quercetin and kaempferol are the most common flavonoids in all the EA fractions. In particular, quercetin in ethanol extract of tartary buckwheat bran showed strong anti-P. acnes activity [51]. The combination of quercetin with kaempferol showed an additive effect on antibacterial activity against P. acnes [52]. However, our results showed that kaempferol is not an anti-P. acnes compound.

Triterpenoids, mainly $19 \alpha$-hydroxyl ursolic acid (pomolic acid) derivatives and 19 $\alpha$-hydroxyl oleanolic acid derivatives, have been reported from SOR $[25,26,53]$. In the UHPLC-QTOF-MS analysis, five triterpenoids (arjunic, euscaphic, tormentic, pomolic, and rosamultic acids) were identified in all EA fractions, although arjunic, euscaphic, and tormentic acids were not separated at each peak under given HPLC conditions. Previously, euscaphic, pomolic, and tormentic acids showed antibacterial activity against P. acnes [54]. Besides, numerous coumarin derivatives from plants showed antibacterial 
activities against Gram-positive and Gram-negative bacteria $[55,56]$. The area of each peak is in proportion to the amount of the particular component present in the sample mixture injected into the HPLC-UV chromatography column. Based on the peak area, quercetin was more distinctive in HWE-EA than in CWE-EA and ME-EA, and coumarin was more distinctive in ME-EA than in CWE-EA and HWE-EA. Previously, methanol was known to be the best solvent to extract coumarins among the organic solvents [57], and some of them were also soluble in hot water [58]. The UHPLC-QTOF-MS supports the presence of quercetin in HWE-EA and coumarin in ME-EA. In this respect, triterpenoids combined with quercetin (HWE-EA) or coumarin (ME-EA) could be responsible for the strong anti-P. acnes activity. This finding explains why the MIC and MBC values of ME-EA were lower than those of CWE-EA and HWE-EA.

\section{Materials and Methods}

\subsection{Plant Material}

The plant specimen (SOR) was purchased from a local market (Korea Medicine Street, Daejeon, Korea) and deposited at the Department of Biology and Medicinal Science, Pai Chai University, Daejeon, Korea.

\subsection{Preparation of Cold Water, Hot Water, and Methanol Extracts, and their Respective Fractions}

Briefly, the SOR was chopped into small pieces and ground to a fine powder using a blender. The powder $(50 \mathrm{~g})$ was extracted for $24 \mathrm{~h}$ with $500 \mathrm{~mL}$ of cold water $\left(4^{\circ} \mathrm{C}\right), 2 \mathrm{~h}$ with $500 \mathrm{~mL}$ of hot water $\left(120^{\circ} \mathrm{C}\right.$, autoclaved), or $24 \mathrm{~h}$ with $500 \mathrm{~mL}$ of methanol in a shaking incubator. All aliquots of each extract were filtered using Whatman No. 1 filter paper (GE Healthcare, Buckinghamshire, UK), reduced to $10 \mathrm{~mL}$ by a vacuum rotary evaporator (EYELA N-N, Tokyo, Japan) at $60^{\circ} \mathrm{C}$, and lyophilized for 4 days to obtain dried powder. The CWE, HWE, and ME yields were 1.8, 3.9, and $2.8 \mathrm{~g}$, respectively, for use as samples after dissolving in dimethyl sulfoxide (DMSO). Furthermore, each dried powder was dissolved in $50 \mathrm{~mL}$ of $50 \%$ methanol and re-extracted successively with equal volumes of n-hexane (fraction 1), EA (fraction 2), n-butanol (fraction 3), and water (fraction 4) in order. Among the four fractions, the EA fractions of the respective extracts exhibited the most active antibacterial activity (data not shown) against P. acnes based on the paper disc diffusion method described below. Therefore, we excluded the other fractions from the subsequent experiments. The respective EA fractions were evaporated at low temperature under reduced pressure, freeze-dried and powdered, and dissolved in DMSO for use as samples.

\subsection{Analysis of the CWE, HWE, ME, and their Respective EA Fractions}

\subsubsection{Determination of Total Phenolic Content}

The total phenolic content in the CWE, HWE, and ME from SOR, and their respective EA fractions, was determined using the Folin-Ciocalteu method [59], with a minor modification. For preparation of the calibration curve, $50 \mu \mathrm{L}$ aliquots of $0.024,0.075,0.105$, and $0.3 \mathrm{mg} / \mathrm{mL}$ of methanolic gallic acid solution were mixed with $500 \mu \mathrm{L}$ of $10 \%$ Folin-Ciocalteau's reagent in water and $400 \mu \mathrm{L}$ of $1 \mathrm{M}$ sodium bicarbonate. After $30 \mathrm{~min}$ of treatment in the dark, the absorption was read at $765 \mathrm{~nm}$ at $20^{\circ} \mathrm{C}$, and the calibration curve was drawn. Fifty microliters of each sample $(1 \mathrm{mg} / \mathrm{mL}$ in methanol) was mixed with the same reagents described above. A reagent blank was also prepared using methanol. After $30 \mathrm{~min}$, the absorption was measured for determination of plant phenolics. The total phenolic content was expressed as gallic acid equivalent (GAE) milligrams per gram of dry powder. All determinations were performed in triplicate. 


\subsubsection{Determination of Total Flavonoid Content}

The total flavonoid content in the CWE, HWE, and ME from SOR, and their respective EA fractions, was determined by Moreno's method [60], with slight modifications. Each sample $(20 \mu \mathrm{L}$ of $1 \mathrm{mg} / \mathrm{mL}$ in methanol) of the CWE, HWE, ME, and their respective EA fractions was mixed with $20 \mu \mathrm{L}$ of $10 \%(w / v)$ aluminum nitrate, $4 \mu \mathrm{L}$ of $1 \mathrm{M}$ potassium acetate, $60 \mu \mathrm{L}$ of methanol, and $112 \mu \mathrm{L}$ of distilled water. The mixture was kept at room temperature for $30 \mathrm{~min}$, and then its absorption at $415 \mathrm{~nm}$ was read using a UV-VIS spectrophotometer Libra S22 (Biochrom Ltd., Cambridge, UK). A standard curve was prepared by measuring the absorption of quercetin solutions in methanol $(0-100 \mu \mathrm{g} / \mathrm{mL})$ under the same conditions. The total flavonoid content was expressed as $\mathrm{mg}$ of quercetin equivalent $(\mathrm{QE}) / \mathrm{g}$ of dry powder. All determinations were performed at least in triplicate.

\subsubsection{Determination of Total Terpenoid Content}

The total terpenoid content in the CWE, HWE, and ME from SOR, and their respective EA fractions, was determined according to the method of Ghorai et al. [61] using linalool as a standard reagent. To $200 \mu \mathrm{L}$ of each sample $(1 \mathrm{mg} / \mathrm{mL}$ in methanol) and $1.5 \mathrm{~mL}$ of chloroform was added. The mixture was vortexed thoroughly and kept for $3 \mathrm{~min}$ at room temperature, then $100 \mu \mathrm{L}$ of concentrated sulfuric acid was added. The microcentrifuge tube containing the reaction mixture was incubated at room temperature for $1.5 \mathrm{~h}$ in the dark. When a reddish brown precipitate formed, the supernatant reaction mixture was gently decanted without disturbing the precipitate. After adding $1.5 \mathrm{~mL}$ of methanol $(95 \%$, $v / v$ ) into the microcentrifuge tube, the precipitate was completely dissolved by vortexing, and the resulting mixture was transferred to a colorimetric cuvette to read the absorbance at $538 \mathrm{~nm}$ against methanol as a blank. The total terpenoid content of each sample was calculated as Linalool equivalents $(\mathrm{mg} / \mathrm{g})$ using the regression equation of the Linalool standard curve $\left(\mathrm{y}=0.012 \mathrm{x}+0.011, \mathrm{r}^{2}=0.982\right)$. All determinations were performed at least in triplicate.

\subsubsection{Determination of Condensed Tannin Content}

The condensed tannin content in the CWE, HWE, and ME from SOR, and their derived EA fractions, was determined according to the method of Sun et al. [62], with minor modifications using catechin as a reference compound. To $400 \mu \mathrm{L}$ of each sample $(1 \mathrm{mg} / \mathrm{mL}$ in methanol), $3 \mathrm{~mL}$ of $4 \%$ vanillin solution in methanol and $1.5 \mathrm{~mL}$ of concentrated $\mathrm{HCl}$ were added. The mixture was allowed to stand for $15 \mathrm{~min}$ at room temperature, and the absorption was measured at $500 \mathrm{~nm}$ against methanol as a blank. The amount of total condensed tannins was expressed as $\mathrm{mg}$ of catechin equivalent (CE)/g of dry powder. All determinations were performed at least in triplicate.

\subsection{Microorganisms and Culture}

The Gram-negative (Escherichia coli and Vibrio parahaemolyticus) and Gram-positive (Listeria monocytogenes, Staphylococcus aureus, and P. acnes) bacteria were used as the test strains. E. coli, $V$. parahaemolyticus, L. monocytogenes, and S. aureus were incubated in LB medium at $37^{\circ} \mathrm{C}$ for $24 \mathrm{~h}$ in a $\mathrm{CO}_{2}$ incubator, whereas P. acnes was incubated in brain-heart infusion (BHI) medium for $48 \mathrm{~h}$ at $37^{\circ} \mathrm{C}$ under anaerobic conditions in an anaerobic jar (Mitsubishi Gas Chemical Co., Tokyo, Japan) with a gas pack.

\subsection{Determination of Antibacterial Activity}

\subsubsection{Paper Disc Diffusion Method}

The antibacterial activities of the samples were initially evaluated by the disc diffusion assay [63]. A sterile cotton swab was dipped into overnight bacterial suspensions of the test strains and used to inoculate over the selective agar (1.5\%) medium by evenly streaking. Stock solutions of the CWE, HWE, $\mathrm{ME}$, and their respective EA fractions were prepared in dimethyl sulfoxide (DMSO) at a concentration 
of $10 \mathrm{mg} / \mathrm{mL}$ and diluted to the concentrations required for the treatments. Paper filter discs $(8 \mathrm{~mm})$ impregnated with $20 \mu \mathrm{L}(1,3$, or $5 \mathrm{mg} /$ disc) of each sample were separately placed on the medium surface. The plates were left for $30 \mathrm{~min}$ at room temperature to allow diffusion of the extracts, and then incubated at $37^{\circ} \mathrm{C}$ for $24 \mathrm{~h}$ for E. coli, V. parahaemolyticus, L. monocytogenes, and S. aureus, and $48 \mathrm{~h}$ anaerobically for $P$. acnes. Finally, the diameters of the inhibition zones around the disc were measured. Kanamycin was included in the test as a reference control to evaluate the susceptibility of the tested strains. The experiments were run in triplicate.

\subsubsection{MIC and MBC}

The $P$. acnes bacteria were prepared at $48 \mathrm{~h} \mathrm{BHI} \mathrm{broth} \mathrm{cultures,} \mathrm{and} \mathrm{the} \mathrm{concentration} \mathrm{was} \mathrm{adjusted}$ to $0.5 \mathrm{OD}_{600 \mathrm{~nm}}$. A diluted bacterial suspension $(100 \mu \mathrm{L})$ was inoculated into each well of a 96-well microplate. The MIC was determined in $\mu \mathrm{g} / \mathrm{mL}$ for the CWE, HWE, ME, and their respective EA fractions using a two-fold serial dilution assay. Each sample was diluted in DMSO to a concentration of $5000 \mu \mathrm{g} / \mathrm{mL}$, and serial dilutions were made to obtain a concentration range from 5000 to $19.5 \mu \mathrm{g} / \mathrm{mL}$. A diluted sample $(100 \mu \mathrm{L})$ was added to each well of the microplate. A medium blank with the selective broth and the sample solution was also prepared for the controls. The MBC was determined by subculturing $100 \mu \mathrm{L}$ of the samples on sterile BHI agar plates from 3 wells that showed no growth during the MIC determination. The plates were incubated following the procedure described for the MIC determination. The MBC was interpreted as the lowest concentration of the sample that showed no growth on the agar plates.

\subsection{In Vitro Antioxidant Activities of the CWE, HWE, ME, and their Respective EA Fractions}

\subsubsection{DPPH Assay}

Each methanolic sample $(1 \mathrm{mg} / \mathrm{mL}$ in methanol) was further diluted using the two-fold method and subjected to the DPPH radical scavenging assay according to the method of Choi et al. [64], with slight modifications. Each diluted sample $(20 \mu \mathrm{L})$ was mixed with $0.2 \mathrm{mM} \mathrm{DPPH}(180 \mu \mathrm{L})$ dissolved in methanol, and the mixture was allowed to react in the dark for $15 \mathrm{~min}$ at room temperature. Methanolic DPPH solution without a sample was used as a control. The absorbance was measured against a blank at $517 \mathrm{~nm}$ and converted into the percent $\mathrm{SC}$ using the following equation: $\% \mathrm{SC}=$ (Absorbance of control - Absorbance of sample) $\times 100 /$ Absorbance of control. The $\mathrm{SC}_{50}$ value was calculated by linear regression of the plots and was defined as the concentration of sample required to reduce $50 \%$ of the DPPH free radicals. All tests were performed at least in triplicate, and the graphs were plotted using the average of three determinations.

\subsubsection{Total Antioxidant Assay}

The total antioxidant activity of the methanolic samples was determined as described by Shabbir et al. [65], with slight modifications. Each sample (100 $\mu \mathrm{L}$ of $1 \mathrm{mg} / \mathrm{mL}$ sample in methanol) was mixed with $600 \mu \mathrm{L}$ of reagent $(0.6 \mathrm{M}$ sulfuric acid, $28 \mathrm{mM}$ sodium phosphate, and $4 \mathrm{mM}$ ammonium molybdate). The mixture was incubated at $95^{\circ} \mathrm{C}$ for $15 \mathrm{~min}$ in a water bath and then cooled to room temperature. The absorbance was measured at $765 \mathrm{~nm}$ using a UV-VIS spectrophotometer against a reagent blank. Quercetin $(1 \mathrm{mg} / \mathrm{mL})$ in methanol was used as a reference, and its total antioxidant activity was defined as $100 \%$. The total antioxidant activity of each sample was expressed relative to that of quercetin. All determinations were performed in triplicate.

\subsubsection{Hydroxide Peroxide Scavenging Assay}

The hydrogen peroxide $\left(\mathrm{H}_{2} \mathrm{O}_{2}\right) \mathrm{SC}$ of the methanolic samples was determined according to the method of Hazra et al. [66]. Each sample (100 $\mu \mathrm{L}$ of a $1 \mathrm{mg} / \mathrm{mL}$ sample in methanol) was mixed with $100 \mu \mathrm{L}$ of hydrogen peroxide $(50 \mathrm{mM})$ and incubated for $30 \mathrm{~min}$ at room temperature. The sample mixture $(90 \mu \mathrm{L})$ was made up to $100 \mu \mathrm{L}$ with HPLC-grade methanol, and $0.9 \mathrm{~mL}$ of the FOX reagent 
(9 volumes of $4.4 \mathrm{mM}$ butylated hydroxytoluene in HPLC-grade methanol: 1 volume of $1 \mathrm{mM}$ xylenol orange and $2.56 \mathrm{mM}$ ammonium ferrous sulfate in $250 \mathrm{mM} \mathrm{H}_{2} \mathrm{SO}_{4}$ ) was added. The total reaction mixture was vortexed and incubated at room temperature for $30 \mathrm{~min}$. The absorbance of the ferric-xylenol orange complex was measured at $560 \mathrm{~nm}$. Quercetin $(1 \mathrm{mg} / \mathrm{mL})$ in methanol was used as a reference, and its SC was defined as $100 \%$. The SC of each sample was expressed relative to that of quercetin. All determinations were performed in triplicate.

\subsubsection{Linoleic Acid Peroxidation Inhibition Assay}

The antioxidant activity of the methanolic samples was also determined in terms of percent inhibition of linoleic acid peroxidation with the following method. Briefly, each sample $(200 \mu \mathrm{L}$ of a $1 \mathrm{mg} / \mathrm{mL}$ sample in methanol) was added to a solution containing $100 \mu \mathrm{L}$ of linoleic acid $(10 \mathrm{mM})$, $100 \mu \mathrm{L}$ of $\mathrm{FeSO}_{4}(10 \mu \mathrm{M})$, and $100 \mu \mathrm{L}$ of ascorbic acid $(2 \mathrm{mM})$, and the reaction mixture was incubated at $37^{\circ} \mathrm{C}$ for $1 \mathrm{~h}$. The reaction was terminated by adding $100 \mu \mathrm{L}$ of TCA $(28 \%)$ and $300 \mu \mathrm{L}$ of thiobarbituric acid (TBA, $1 \%$ ), followed by incubation at $80{ }^{\circ} \mathrm{C}$ for $1 \mathrm{~h}$. Lipid peroxide reacts with TBA to form thiobarbituric acid reactive substances (TBARS); its absorbance at $532 \mathrm{~nm}$ was measured to quantify the TBARS. Quercetin was used as a standard for comparison.

\subsection{HPLC Analysis}

The lyophilized fractions of the CWE-EA, HWE-EA, and ME-EA were reconstituted in $1 \mathrm{~mL}$ of $20 \%$ aqueous methanol $(v / v)$ and passed through a $0.2 \mu \mathrm{m}$ nylon filter. Eleven standards were included for flavonoids (quercetin and kaempferol), triterpenoids (arjunic acid and euscaphic acid), polyphenols (caffeic acid, chlorogenic acid, ferulic acid, gallic acid, tannic acid, and coumarin), and kojic acid. Chromatographic separations were performed on an Agilent Zorbax Eclipse XDB-C18 (Agilent, Santa Clara, CA, USA) column $(4.6 \mathrm{~mm} \times 150 \mathrm{~mm}, 5 \mu \mathrm{m})$. Samples $(10 \mu \mathrm{L})$ were injected into the HPLC instrument (Shimadzu Prominence LC 20A series HPLC system, Shimadzu Corp, Kyoto, Japan) with a PDA detector. The mobile phase for CWE-EA, HWE-EA, and ME-EA consisted of $0.1 \%$ phosphoric acid in water (solvent $\mathrm{A}$ ) and $0.1 \%$ phosphoric acid in acetonitrile (solvent $\mathrm{B}$ ). Elution from the column was achieved with the following gradient: $0-5 \mathrm{~min}, 97 \% \mathrm{~A}$ and $3 \% \mathrm{~B} ; 15-20 \mathrm{~min}, 90 \% \mathrm{~A}$ and $10 \% \mathrm{~B}$; $30-40 \mathrm{~min}, 50 \% \mathrm{~A}$ and $50 \% \mathrm{~B} ; 40.1-50 \mathrm{~min}, 97 \% \mathrm{~A}$ and $3 \% \mathrm{~B}$. The preparative system was run for $40 \mathrm{~min}$ of the total running time at a constant flow rate of $0.8 \mathrm{~mL} / \mathrm{min}$ at ambient temperature, and the spectrum was monitored at $272 \mathrm{~nm}$. The identification of each compound was based on a combination of the retention time and UV spectral matching.

\subsection{UHPLC-QTOF-MS}

The mass spectrometry system was a 1290 Infinity II Ultra High Performance Liquid Chromatography (Agilent, Santa Clara, CA, USA) Triple TOF 5600 plus time of flight mass spectrometer, equipped with electrospray ionization (ESI) source TripleTOF ${ }^{\circledR} 5600+($ AB SCIEX, Framingham, MA, USA). The mobile phase for CWE-EA and HWE-EA consisted of $2 \%$ acetic acid in water (solvent A) and $2 \%$ acetic acid in $50 \%$ acetonitrile (solvent $B$ ), whereas the mobile phase for ME-EA consisted of $2 \%$ acetic acid in water (solvent $\mathrm{A}$ ) and $2 \%$ acetic acid in $100 \%$ methanol (solvent $\mathrm{B}$ ). The MS analysis was performed by ESI positive ion scanning mode. The conditions of the ESI source were as follows: Drying gas flow rate, $10 \mathrm{~L} / \mathrm{min}$; drying gas temperature, $400{ }^{\circ} \mathrm{C}$; sheath gas flow rate, $10 \mathrm{~L} / \mathrm{min}$; sheath gas temperature, $400{ }^{\circ} \mathrm{C}$; nebulizer, $45 \mathrm{psi}$; capillary voltage, $4500 \mathrm{~V}$; fragmentor voltage, $180 \mathrm{~V}$; mass range of 100-1000 m/z; scan rate, $3 \mathrm{~Hz}$. The resolution was 35,000 FWHM. Data acquisition and processing were done using PeakView ${ }^{\circledR} 2.2$ and MasterView ${ }^{\mathrm{TM}} 1.1$ (AB SCIEX, Framingham, MA, USA). Confidence of the compound identification was based on accurate mass, error mass (+/ - 3.0 ppm), and isotope difference $(<20 \%)$, and expressed by an overall identification score computed as a weighted average of the compound isotopic signals, such as exact mass, relative abundances, and $m / z$ distances. To determine the anti-P. acnes activity of the identified compounds, nine standards were tested using the paper disc diffusion method described above. 


\subsection{Statistical Analysis}

The statistical analysis was performed using one-way analysis of variance (ANOVA) followed by Duncan's multiple range test in the SPSS software (version 19.0, SPSS Inc., Chicago, IL, USA) $(p<0.05)$. Pearson's correlation coefficients (http:/ / www.socscistatistics.com) were used to determine whether the antibacterial activity or antioxidant activity was associated with the total phenolic, flavonoid, terpenoid and condensed tannin contents $(p<0.01$ or $p<0.05)$.

\section{Conclusions}

The present investigation demonstrated that the SOR CWE, HWE, ME, and their respective EA fractions had strong anti-P. acnes and antioxidant activities. The majority of phenolic acids, flavonoids, and tannins were identified in all EA fractions, and were considered to be responsible for the antioxidant activity of SOR. On the other hand, triterpenoids (euscaphic acid) combined with quercetin (HWE-EA) or coumarin (ME-EA) could be responsible for the strong anti-P. acnes activity of SOR.

Supplementary Materials: The following are available online, Table S1: Effect of various extracts from roots of S. officinalis L. on the bacterial growth determined by paper disc diffusion assay. Figure S1, UHPLC-QTOF-MS spectra of major compounds in SOR CWE-EA; Figure S2, UHPLC-QTOF-MS spectra of major compounds in SOR HWE-EA.

Author Contributions: S.K. and S.O. contributed equally to this work, and performed the experiments and statistical analyses. H.B.N., S.J., S.H.L., and J.M.K. supported sample preparation and the experiments. H.P.J. acquired funding as the principal investigator. C.W.C. designed the experiments, wrote the original draft of the manuscript, and acquired funding as the co-principal investigator. All authors have read and approved the final version of the manuscript.

Funding: This research work was supported by the Bio-industry Technology Development Program [No. 315053031WT011] from the Ministry of Agriculture, Food, and Rural Affairs, Republic of Korea, through the IPET.

Acknowledgments: The authors are grateful to Emeritus Sei Chang Kim for collection of the plant material and for providing his research facilities.

Conflicts of Interest: The authors declare no conflict of interest.

\section{References}

1. Aydemir, E.H. Acne vulgaris. Turk. Pediatr. Ars. 2014, 49, 13-16. [CrossRef] [PubMed]

2. Graham, G.M.; Farrar, M.D.; Cruse-Sawyer, J.E.; Holland, K.T.; Ingham, E. Proinflammatory cytokine production by human keratinocytes stimulated with Propionibacterium acnes and P. acnes GroEL. Br. J. Dermatol. 2004, 150, 421-428. [CrossRef] [PubMed]

3. Tan, A.U.; Schlosser, B.J.; Paller, A.S. A review of diagnosis and treatment of acne in adult female patients. Int. J. Womens Dermatol. 2018, 4, 56-71. [CrossRef] [PubMed]

4. Zaenglein, A.L.; Pathy, A.L.; Schlosser, B.J.; Alikhan, A.; Baldwin, H.E.; Berson, D.S.; Bowe, W.P.; Graber, E.M.; Harper, J.C.; Kang, S.; et al. Guidelines of care for the management of acne vulgaris. J. Am. Acad. Dermatol. 2016, 74, 945-973. [CrossRef] [PubMed]

5. Alexis, A.F. Clinical considerations on the use of concomitant therapy in the treatment of acne. J. Dermatol. Treat. 2008, 19, 199-209. [CrossRef] [PubMed]

6. Elston, D.M. Topical antibiotics in dermatology: Emerging patterns of resistance. Dermatol. Clin. 2009, 27, 25-31. [CrossRef] [PubMed]

7. Humphrey, S. Antibiotic resistance in acne treatment. Skin Therapy Lett. 2012, 17, 1-3. [PubMed]

8. Kanlayavattanakul, M.; Lourith, N. Therapeutic agents and herbs in topical application for acne treatment. Int. J. Cosmet. Sci. 2011, 33, 289-297. [CrossRef] [PubMed]

9. Karkanis, A.; Vellios, E.; Thomaidis, T.; Bilalis, D.; Efthimiadou, A.; Travlos, I. Phytochemistry and biological properties of burnet weed (Sanguisorba spp.): A review. Not. Sci. Biol. 2014, 6, 395-398. [CrossRef]

10. Nguyen, T.T.; Cho, S.O.; Ban, J.Y.; Kim, J.Y.; Ju, H.S.; Koh, S.B.; Song, K.-S.; Seong, Y.H. Neuroprotective effect of Sanguisorbae radix against oxidative stress-induced brain damage: In vitro and in vivo. Biol. Pharm. Bull. 2008, 31, 2028-2035. [CrossRef] [PubMed] 
11. Zhang, L.; Koyyalamudi, S.R.; Jeong, S.C.; Reddy, N.; Smith, P.T.; Ananthan, R.; Longvah, T. Antioxidant and immunomodulatory activities of polysaccharides from the roots of Sanguisorba officinalis. Int. J. Biol. Macromol. 2012, 51, 1057-1062. [CrossRef] [PubMed]

12. Cai, Z.; Li, W.; Wang, H.; Yan, W.; Zhou, Y.; Wang, G.; Cui, J.; Wang, F. Anti-tumor and immunomodulating activities of a polysaccharide from the root of Sanguisorba officinalis L. Int. J. Biol. Macromol. 2012, 51, 484-488. [CrossRef] [PubMed]

13. Wang, Z.; Loo, W.T.; Wang, N.; Chow, L.W.C.; Wang, D.; Han, F.; Zheng, X.; Chen, J.-P. Effect of Sanguisorba officinalis L on breast cancer growth and angiogenesis. Expert Opin. Ther. Targets 2012, 16, S79-S89. [CrossRef] [PubMed]

14. Shin, J.A.; Kim, J.S.; Kwon, K.H.; Nam, J.S.; Jung, J.Y.; Cho, N.P.; Cho, S.D. Apoptotic effect of hot water extract of Sanguisorba officinalis L. in human oral cancer cells. Oncol. Lett. 2012, 4, 489-494. [CrossRef] [PubMed]

15. Choi, E.S.; Kim, J.S.; Kwon, K.H.; Kim, H.S.; Cho, N.P.; Cho, S.D. Methanol extract of Sanguisorba officinalis L. with cytotoxic activity against PC3 human prostate cancer cells. Mol. Med. Rep. 2012, 6, 670-674. [CrossRef] [PubMed]

16. Liu, M.-P.; Liao, M.; Dai, C.; Chen, J.-F.; Yang, C.-J.; Liu, M.; Chen, Z.-G.; Yao, M.-C. Sanguisorba officinalis L. synergistically enhanced 5-fluorouracil cytotoxicity in colorectal cancer cells by promoting a reactive oxygen species-mediated, mitochondria-caspase-dependent apoptotic pathway. Sci. Rep. 2016, 6, 34245. [CrossRef] [PubMed]

17. Yu, T.; Lee, Y.J.; Yang, H.M.; Han, S.; Kim, J.H.; Lee, Y.; Kim, C.; Han, M.H.; Kim, M.-Y.; Lee, J.; et al. Inhibitory effect of Sanguisorba officinalis ethanol extract on $\mathrm{NO}$ and $\mathrm{PGE}_{2}$ production is mediated by suppression of NF- $\mathrm{BB}$ and AP-1 activation signaling cascade. J. Ethnopharmacol. 2011, 134, 11-17. [CrossRef] [PubMed]

18. Yang, J.H.; Hwang, Y.H.; Gu, M.J.; Cho, W.K.; Ma, J.Y. Ethanol extracts of Sanguisorba officinalis L. suppress TNF- $\alpha /$ IFN- $\gamma$-induced pro-inflammatory chemokine production in HaCaT cells. Phytomedicine 2015, 22, 1262-1268. [CrossRef] [PubMed]

19. Menković, N.; Zdunić, G.; Šavikin, K.; Stanojković, T.; Juranić, Z.; Janković, T. Preliminary investigation of cytotoxic and antioxidant activity of some medicinal plants growing in Serbia and Montenegro. Planta Med. 2007, 73, 043. [CrossRef]

20. Zhang, S.; Liu, X.; Zhang, Z.L.; He, L.; Wang, Z.; Wang, G.S. Isolation and identification of the phenolic compounds from the roots of Sanguisorba officinalis L. and their antioxidant activities. Molecules 2012, 17, 13917-13922. [CrossRef] [PubMed]

21. Seo, C.-S.; Jeong, S.-J.; Yoo, S.-R.; Lee, N.-R.; Shin, H.-K. Quantitative analysis and in vitro anti-inflammatory effects of gallic acid, ellagic acid, and quercetin from Radix Sanguisorbae. Pharmacogn. Mag. 2016, 12, 104-108. [PubMed]

22. Kim, T.G.; Kang, S.Y.; Jung, K.K.; Kang, J.H.; Lee, E.; Han, H.M.; Kim, S.H. Antiviral activities of extracts isolated from Terminalis chebula retz., Sanguisorba officinalis L., Rubus coreanus miq. and Rheum palmatum L. against hepatitis B virus. Phytother. Res. 2001, 15, 718-720. [CrossRef] [PubMed]

23. Liang, J.; Chen, J.; Tan, Z.; Peng, J.; Zheng, X.; Nishiura, K.; Ng, J.; Wang, Z.; Wang, D.; Chen, Z.; et al. Extracts of medicinal herb Sanguisorba officinalis inhibit the entry of human immunodeficiency virus type one. J. Food Drug Anal. 2013, 21, S52-S58. [CrossRef] [PubMed]

24. Kim, Y.H.; Chung, C.B.; Kim, J.G.; Ko, K.I.; Park, S.H.; Kim, J.-H.; Eom, S.Y.; Kim, Y.S.; Hwang, Y.-I.; Kim, K.H. Anti-wrinkle activity of ziyuglycoside I isolated from a Sanguisorba officinalis root extract and its application as a cosmeceutical ingredient. Biosci. Biotechnol. Biochem. 2008, 72, 303-311. [CrossRef] [PubMed]

25. Mimaki, Y.; Fukushima, M.; Yokosuka, A.; Sashida, Y.; Furuya, S.; Sakagami, H. Triterpene glycosides from the roots of Sanguisorba officinalis. Phytochemistry 2001, 57, 773-779. [CrossRef]

26. Liu, X.; Cui, Y.; Yu, Q.; Yu, B. Triterpenoids from Sanguisorba officinalis. Phytochemistry 2005, 66, 1671-1679. [CrossRef] [PubMed]

27. Sun, W.; Zhang, Z.L.; Liu, X.; Zhang, S.; He, L.; Wang, Z.; Wang, G.-S. Terpene glycosides from the roots of Sanguisorba officinalis L. and their hemostatic activities. Molecules 2012, 17, 7629-7636. [CrossRef] [PubMed]

28. Hu, J.; Song, Y.; Li, H.; Yang, B.; Mao, X.; Zhao, Y.; Shi, X. Cytotoxic triterpene glycosides from the roots of Sanguisorba officinalis. Arch. Pharm. Res. 2015, 38, 984-990. [CrossRef] [PubMed]

29. Xie, Y.; Yang, W.; Tang, F.; Chen, X.; Ren, L. Antibacterial activities of flavonoids: Structure-activity relationship and mechanism. Curr. Med. Chem. 2015, 22, 132-149. [CrossRef] [PubMed] 
30. Kim, S.H.; Kim, D.K.; Eom, D.O.; Kim, S.Y.; Kim, S.H.; Shin, T.Y. Sanguisorba officinalis inhibits immediate-type allergic reactions. Nat. Prod. Sci. 2002, 8, 177-182.

31. Shan, B.; Cai, Y.Z.; Brooks, J.D.; Corke, H. The in vitro antibacterial activity of dietary spice and medicinal herb extracts. Int. J. Food Microbiol. 2007, 117, 112-119. [CrossRef] [PubMed]

32. Gawron-Gzella, A.; Witkowska-Banaszczak, E.; Bylka, W.; Dudek-Makuch, M.; Odwrot, A.; Skrodzka, N. Chemical composition, antioxidant and antimicrobial activities of Sanguisorba officinalis L. extracts. Pharm. Chem. J. 2016, 50, 244-249. [CrossRef]

33. Ginovyan, M.; Petrosyan, M.; Trchounian, A. Antimicrobial activity of some plant materials used in Armenian traditional medicine. BMC Complement. Altern. Med. 2017, 17, 50. [CrossRef] [PubMed]

34. Shin, S.W.; Ghimeray, A.K.; Park, C.H. Investigation of total phenolic, total flavonoid, antioxidant and allyl isothiocyanate content in the different organs of Wasabi japonica grown in an organic system. Afr. J. Tradit. Complement. Altern. Med. 2014, 11, 38-45. [CrossRef] [PubMed]

35. Gálvez, M.; Martín-Cordero, C.; Houghton, P.J.; Ayuso, M.J. Antioxidant activity of methanol extracts obtained from Plantago species. J. Agric. Food Chem. 2005, 53, 1927-1933. [CrossRef] [PubMed]

36. Kokoska, L.; Polesny, Z.; Rada, V.; Nepovim, A.; Vanek, T. Screening of some Siberian medicinal plants for antimicrobial activity. J. Ethnopharmacol. 2002, 82, 51-53. [CrossRef]

37. Lee, H.A.; Hong, S.; Oh, H.G.; Park, S.H.; Kim, Y.C.; Park, H.; Jeong, G.S.; Kim, O. Antibacterial activity of Sanguisorba officinalis against Helicobacter pylori. Lab. Anim. Res. 2010, 26, 257-263. [CrossRef]

38. Mahboubi, A.; Asgarpanah, J.; Sadaghiyani, P.N.; Faizi, M. Total phenolic and flavonoid content and antibacterial activity of Punica granatum L. var. pleniflora flowers (Golnar) against bacterial strains causing foodborne diseases. BMC Complement. Altern. Med. 2015, 15, 366. [CrossRef] [PubMed]

39. Mansouri, A.; Embared, G.; Kokkalou, E.; Kefalas, P. Phenolic profile and antioxidant activity of the Algerian ripe date palm fruit (Phoenix dactylifera). Food Chem. 2005, 89, 411-420. [CrossRef]

40. Hussain, A.I.; Rathore, H.A.; Sattar, M.Z.A.; Chatha, S.A.S.; Ahmad, F.; Ahmad, A.; Johns, E.J. Phenolic profile and antioxidant activity of various extracts from Citrullus colocynthis (L.) from the Pakistani flora. Ind. Crops Prod. 2013, 45, 416-422. [CrossRef]

41. Cai, Y.; Luo, Q.; Sun, M.; Corke, H. Antioxidant activity and phenolic compounds of 112 traditional Chinese medicinal plants associated with anticancer. Life Sci. 2004, 74, 2157-2184. [CrossRef] [PubMed]

42. Abdel-Hameed, E.-S.S. Total phenolic contents and free radical scavenging activity of certain Egyptian Ficus species leaf samples. Food Chem. 2009, 114, 1271-1277. [CrossRef]

43. Rebaya, A.; Belghith, S.I.; Baghdikian, B.; Leddet, V.M.; Mabrouki, F.; Olivier, E.; Cherif, J.K.; Ayadi, M.T. Total phenolic, total flavonoid, tannin content, and antioxidant capacity of Halimium halimifolium (Cistaceae). J. Appl. Pharm. Sci. 2014, 5, 52-57.

44. Redondo, L.M.; Chacana, P.A.; Dominguez, J.E.; Fernandez Miyakawa, M.E. Perspectives in the use of tannins as alternative to antimicrobial growth promoter factors in poultry. Front. Microbiol. 2014, 5, 118. [CrossRef] [PubMed]

45. Akiyama, H.; Fujii, K.; Yamasaki, O.; Oono, T.; Iwatsuki, K. Antibacterial action of several tannins against Staphylococcus aureus. J. Antimicrob. Chemother. 2001, 48, 487-491. [CrossRef] [PubMed]

46. Vu, T.T.; Kim, H.; Tran, V.K.; Vu, H.D.; Hoang, T.X.; Han, J.W.; Choi, Y.H.; Jang, K.S.; Choi, G.J.; Kim, J.-C. Antibacterial activity of tannins isolated from Sapium baccatum extract and use for control of tomato bacterial wilt. PLoS ONE 2017, 12, e0181499. [CrossRef] [PubMed]

47. Borges, A.; Ferreira, C.; Saavedra, M.J.; Simões, M. Antibacterial activity and mode of action of ferulic and gallic acids against pathogenic bacteria. Microb. Drug Resist. 2013, 19, 256-265. [CrossRef] [PubMed]

48. Kepa, M.; Miklasińska-Majdanik, M.; Wojtyczka, R.D.; Idzik, D.; Korzeniowski, K.; Smoleń-Dzirba, J.; Wasik, T.J. Antimicrobial potential of caffeic acid against Staphylococcus aureus clinical strains. Biomed Res. Int. 2018, 2018. [CrossRef] [PubMed]

49. Elizondo, A.M.; Mercado, E.C.; Rabinovitz, B.C.; Fernandez Miyakawa, M.E. Effect of tannins on the in vitro growth of Clostridium perfringens. Veter. Microbiol. 2010, 145, 308-314. [CrossRef] [PubMed]

50. Mierziak, J.; Kostyn, K.; Kulma, A. Flavonoids as important molecules of plant interactions with the environment. Molecules 2014, 19, 16240-16265. [CrossRef] [PubMed]

51. Wang, L.; Yang, X.; Qin, P.; Shan, F.; Ren, G. Flavonoid composition, antibacterial and antioxidant properties of tartary buckwheat bran extract. Ind. Crops Prod. 2013, 49, 312-317. [CrossRef] 
52. Lim, Y.H.; Kim, I.H.; Seo, J.J. In vitro activity of kaempferol isolated from the Impatiens balsamina alone and in combination with erythromycin or clindamycin against Propionibacterium acnes. J. Microbiol. 2007, 45, 473-477. [PubMed]

53. Liu, X.; Shi, B.; Yu, B. Four new dimeric triterpene glucosides from Sanguisorba officinalis. Tetrahedron 2004, 60, 11647-11654. [CrossRef]

54. Tan, H.; Sonam, T.; Shimizu, K. The potential of triterpenoids from loquat leaves (Eriobotrya japonica) for prevention and treatment of skin disorder. Int. J. Mol. Sci. 2017, 18, 1030. [CrossRef] [PubMed]

55. Tada, Y.; Shikishima, Y.; Takaishi, Y.; Shibata, H.; Higuti, T.; Honda, G.; Ito, M.; Takeda, Y.; Kodzhimatov, O.K.; Ashurmetov, O.; et al. Coumarins and $\gamma$-pyrone derivatives from Prangos pabularia: antibacterial activity and inhibition of cytokine release. Phytochemistry 2002, 59, 649-654. [CrossRef]

56. Basile, A.; Sorbo, S.; Spadaro, V.; Bruno, M.; Maggio, A.; Faraone, N.; Rosselli, S. Antimicrobial and antioxidant activities of coumarins from the roots of Ferulago campestris (Apiaceae). Molecules 2009, 14, 939-952. [CrossRef] [PubMed]

57. Sproll, C.; Ruge, W.; Andlauer, C.; Godelmann, R.; Lachenmeier, D.W. HPLC analysis and safety assessment of coumarin in foods. Food Chem. 2008, 109, 462-469. [CrossRef] [PubMed]

58. Medeiros-Neves, B.; de Barros, F.M.C.; von Poser, G.L.; Teixeira, H.F. Quantification of coumarins in aqueous extract of Pterocaulon balansae (Asteraceae) and characterization of a new compound. Molecules 2015, 20, 18083-18094. [CrossRef] [PubMed]

59. Ainsworth, E.A.; Gillespie, K.M. Estimation of total phenolic content and other oxidation substrates in plant tissues using Folin-Ciocalteu reagent. Nat. Protoc. 2007, 2, 875-877. [CrossRef] [PubMed]

60. Moreno, M.I.N.; Isla, M.I.; Sampietro, A.R.; Vattuone, M.A. Comparison of the free radical-scavenging activity of propolis from several regions of Argentina. J. Ethnopharmacol. 2000, 71, 109-114. [CrossRef]

61. Ghorai, N.; Chakraborty, S.; Gucchait, S.; Saha, S.K.; Biswas, S. Estimation of total terpenoids concentration in plant tissues using a monoterpene, linalool as standard reagent. Protoc. Exch. 2012, 5. [CrossRef]

62. Sun, B.; Ricardo-da-Silva, J.M.; Spranger, I. Critical factors of vanillin assay for catechins and proanthocyanidins. J. Agric. Food Chem. 1998, 46, 4267-4274. [CrossRef]

63. Boussaada, O.; Chriaa, J.; Nabli, R.; Ammar, S.; Saidana, D.; Mahjoub, M.A.; Chraeif, I.; Helal, A.N.; Mighri, Z. Antimicrobial and antioxidant activities of methanol extracts of Evax pygmaea (Asteraceae) growing wild in Tunisia. World J. Microbiol. Biotechnol. 2008, 24, 1289-1296. [CrossRef]

64. Choi, C.W.; Kim, S.C.; Hwang, S.S.; Choi, B.K.; Ahn, H.J.; Lee, M.Y.; Park, S.H.; Kim, S.K. Antioxidant activity and free radical scavenging capacity between Korean medicinal plants and flavonoids by assay-guided comparison. Plant Sci. 2002, 163, 1161-1168. [CrossRef]

65. Shabbir, M.; Khan, M.R.; Saeed, N. Assessment of phytochemicals, antioxidant, anti-lipid peroxidation and anti-hemolytic activity of extract and various fractions of Maytenus royleanus leaves. BMC Complement. Altern. Med. 2013, 13, 143. [CrossRef] [PubMed]

66. Hazra, B.; Biswas, S.; Mandal, N. Antioxidant and free radical scavenging activity of Spondias pinnata. BMC Complement. Altern. Med. 2008, 8, 63. [CrossRef] [PubMed]

Sample Availability: Samples of the compounds are available from the authors.

(C) 2018 by the authors. Licensee MDPI, Basel, Switzerland. This article is an open access article distributed under the terms and conditions of the Creative Commons Attribution (CC BY) license (http:/ / creativecommons.org/licenses/by/4.0/). 